Artigos

Volume 8 - 2018|n. 12

\title{
Educação Infantil no Município de Teresina: perfil formativo dos docentes
}

\author{
Sandra Regina de Morais Cunha Rodrigues \\ Universidade Federal do Piauí (UFPI), Teresina/PI - Brasil \\ Instituto Federal do Piauí (IFPI), Teresina/PI - Brasil \\ Luis Carlos Sales \\ Universidade Federal do Piauí (UFPI), Teresina/PI - Brasil
}

\section{Resumo}

Este artigo apresenta um estudo sobre o perfil da formação inicial do professor de Educação Infantil do Município de Teresina, considerando a exigência da LDB n 9.394/96 que trata da formação mínima exigida para atuar nessa etapa de Educação Básica. O estudo compreendeu o universo de 2.342 docentes que atuavam na rede municipal e privada desse município. Trata-se de uma pesquisa de abordagem quantitativa, tendo como fonte os Microdados do Censo Escolar da Educação Básica do ano de 2017, disponibilizados no portal INEP. A extração desses Microdados e a posterior análise estatística foram realizadas com o auxílio do SPSS. A pesquisa revelou que, apesar dos avanços, o perfil de formação dos professores é diversificado. No entanto, considerando o percentual de docentes que já possuíam e estavam cursando licenciatura em Pedagogia, pode-se projetar uma melhoria desse perfil formativo a curto ou médio prazo.

Palavras-chave: Política Educacional. Educação Infantil. Valorização Docente. Perfil Formativo.

\section{Early Childhood Education in Teresina, Piauí state, Brazil: teacher's}

\section{training profile}

\section{Abstract}

This article presents a study on the profile of the baseline education of Early Education teachers from Teresina, Brazil. It considers the requirement of the National Educational Bases and Guidelines Law (LDB 9394/1996) concerning the minimum training required to work at this level of K-12 Education. The study comprised the universe of 2,342 teachers who worked in the public and private system of this city. It was used a quantitative approach based on the microdata of the K-12 Education School Census from 2017, available on the INEP website. The microdata collection and the subsequent statistical analysis were performed by means of SPSS. The research showed that despite the progress, the teacher's training profile is diversified. However, considering the percentage of teachers who already had taken and were taking a degree in Pedagogy, an improvement of this training profile can be projected in the short- or medium-term.

Keywords: Educational Policy. Early Childhood Education. Teacher Appreciation. Training Profile. 
Educação Infantil no Município de Teresina

\section{Introdução}

O percurso histórico da formação dos professores da Educação Infantil revela que essa etapa da Educação Básica, até bem pouco tempo, era ofertada como uma atividade de caráter assistencialista, partindo da lógica de que eram espaços escolares responsáveis apenas pelo cuidado e socialização das crianças, ficando, durante um longo período, em segundo plano na política educacional brasileira. O atendimento ocorria por um campo diversificado de instituições filantrópicas e associações comunitárias, as quais funcionavam em estruturas, na maioria das vezes, improvisadas. Isso implicou numa compreensão equivocada de que, para cuidar de crianças, não seria necessário ter educação, o que, por sua vez, resultava na ausência de políticas de formação para os docentes envolvidos nesse processo.

A Constituição Federal de 1988 determinou o dever do Estado com a oferta da Educação Infantil às crianças de até 5 (cinco) ${ }^{1}$ anos de idade, pelo art. 208. Com a Lei de Diretrizes e Bases da Educação Nacional, LDB n 9.394/96, essa etapa da Educação Básica passa a ter finalidades e organização no âmbito dos sistemas de ensino. Quanto à oferta, essa Lei estabelece, no Art. 30, que a Educação Infantil para crianças de até três anos de idade será ofertada em creches, ou entidades equivalentes, admitindo "[...] o (res)surgimento de outros tipos de instituições de atendimento à tenra idade e a continuidade da filantropia e do atendimento domiciliar, contrariando as lutas históricas por um atendimento educacional igualitário" (LIMA, 2016, p. 24), haja vista admitir a oferta desse atendimento por instituições privadas de natureza não escolar.

Contudo, um importante avanço provocado pelo reconhecimento da Educação Infantil como direito da criança e um dever do Estado diz respeito à formação do professor, o que resultou no desenvolvimento de políticas de formação de professores, por meio de ações, programas de formação inicial e continuada, contribuindo para uma significativa melhoria no perfil formativo dos professores.

Esta pesquisa objetivou investigar o perfil da formação inicial do professor de Educação Infantil do Município de Teresina, considerando a exigência da LDB n 9.394/96 que trata da formação mínima exigida para atuar nessa etapa de Educação Básica, problematizando os elementos de convergências e divergências entre o referido marco legal e o perfil formativo encontrado. O estudo compreendeu o universo de 2.342 docentes que atuavam na rede municipal e privada, em 2017. A seguir é apresentado, de forma sucinta, o percurso metodológico do trabalho.

\section{Metodologia}

Considerando as características do objeto de estudo, optou-se por uma pesquisa de abordagem quantitativa, classificada, quanto ao objetivo elencado, como descritivo-analítica, tendo como fonte os Microdados do Censo Escolar da Educação Básica do Instituto Nacional de Estudos e Pesquisa Anísio Teixeira (INEP), do ano de 2017, no tocante, especificamente, à formação dos professores que atuam na Educação Infantil. Os Microdados estão organizados por banco de escola, turma, docente e aluno, relacionando o código da turma, da escola e do professor.

1 A Emenda Constitucional $n^{\circ} 53$ de 2006 alterou a idade, antes era de até 6 (seis) anos. 
Educação Infantil no Município de Teresina

A extração dos Microdados e a posterior análise estatística foram desenvolvidas com o auxílio do Programa Statistical Package for the Social Siences (SPSS). Dessa forma, a elaboração das tabelas foi realizada utilizando algumas funções ${ }^{2}$ do referido Programa. A Tabela 4, referente ao tipo de primeira graduação por dependência administrativa, foi construída a partir da identificação dos códigos ${ }^{3}$ dos cursos superiores, os quais os docentes da Educação Infantil de Teresina cursaram ou estavam cursando. Para facilitar a análise, os vários cursos encontrados foram agrupados em três grandes categorias: Licenciatura em Pedagogia, outras licenciaturas e bacharelado.

Para realização desta pesquisa, inicialmente realizou-se um estudo bibliográfico acerca da formação de professores no Brasil, bem como a análise da legislação que institui e regulamenta a política de formação docente em âmbito nacional, estadual e municipal.

$\mathrm{Na}$ sequência, são apresentados os aspectos legais sobre a formação inicial de professores para a Educação Infantil.

\section{Formação Inicial de Professores para Educação Infantil: o que estabelece a legislação}

A LDB estabelece diretrizes para ampliação da oferta na Educação Infantil, no entanto, não avançou quanto às exigências mínimas do perfil de formação dos professores para atuar nessa etapa da Educação Básica. Nesse sentido, há necessidade de se repensar os processos formativos dos professores, como requisito mínimo para realizar um atendimento com qualidade, tendo em vista que a LDB ao mesmo tempo em que determina que a formação de docentes para a educação Básica deverá ser realizada em nível superior, em curso de licenciatura plena, mantém um ponto controverso, que é o fato de se continuar admitindo o curso Normal de Nível Médio como formação inicial mínima para o exercício do magistério, tanto na Educação Infantil quanto nos anos iniciais do Ensino Fundamental ( $1^{\circ}$ ao $5^{\circ}$ ano), uma formação técnica, que não proporciona ao professor fundamentação teórica acerca do desenvolvimento da criança.

Prevalecem, desse modo, dois diferentes modelos para o desenvolvimento de políticas públicas para a formação de professores. Um referente aos cursos superiores, ofertados pelas universidades e institutos superiores; o outro, a permanência do curso Normal Magistério de nível médio, em observância ao artigo supracitado, a Lei estabelece, no parágrafo $4^{\circ}$ do Artigo 87 das Disposições Transitórias, que até o final da Década da Educação (1997-2007) somente seriam admitidos professores habilitados em nível superior ou formados por treinamento em serviço.

Portanto, os sistemas de ensino contariam com um prazo de dez anos para que fizessem as devidas adequações à nova exigência quanto à formação dos professores em nível superior. Segundo Gatti e Barretto (2009), esse prazo seria necessário na medida em que, no Brasil, nessa época, a maioria dos professores do primeiro segmento do Ensino

2 Dados/seleção de casos, dados/agregar, analisar/estatísticas descritivas/frequência, analisar/estatísticas descritivas/frequência/tabela, analisa/estatísticas descritivas/tabela de referência cruzada

3 Código de cursos superiores da Organização de Cooperação e de Desenvolvimento Econômico (OCDE), disponível como anexo 5 no banco de microdados do censo escolar da educação básica de 2017. 
Educação Infantil no Município de Teresina

Fundamental possuía formação no magistério, em nível médio, o que demandaria tempo, muito esforço e financiamento para efetivar a formação desses docentes em nível superior.

Para Gatti (2006), o duplo modelo de proposta para a formação do professor trouxe algumas implicações. Uma delas é a manutenção do Curso de Magistério de Nível Médio, uma formação simplificada que limita o conhecimento do professor, ignorando os princípios das Diretrizes Curriculares Nacionais para a Educação Infantil (BRASIL, 2010) e Parâmetros Nacionais de Qualidade para a Educação Infantil (BRASIL, 2006), razão pela qual muitos optaram por ele, como meio de obtenção imediata de emprego em pequenas escolas ou um contrato em condições precárias em alguns municípios e estados, que têm optado pela contratação temporária desses profissionais.

Ademais, o Plano Nacional de Educação (2014-2024), instituído pela Lei $\mathrm{n}^{\circ}$ $13.005 / 2014$, busca, predominantemente, em sua Meta 15, assegurar que todos os professores da Educação Básica tenham formação específica de nível superior, obtida em curso de licenciatura na área específica em que atuam, por meio de uma política nacional de formação dos profissionais da educação em regime de colaboração entre a União, os estados, o Distrito Federal e os municípios. A estratégia 1.8 (da Meta 1 do PNE), embora sem indicar uma data intermediária, assim estabelece: "promover a formação inicial e continuada dos(as) profissionais da educação infantil, garantindo, progressivamente, o atendimento por profissionais com formação superior". Portanto, o PNE aponta para a necessidade de se ter, em toda a educação básica, docentes com formação em nível superior.

\section{Contribuições do FUNDEB para a Política de Formação Docente}

Com o advento da Constituição Federal de 1988, houve uma elevação dos percentuais dos impostos vinculados à educação, aumentando os recursos para sua promoção. Essa carta magna estabelece que os estados, os municípios e o Distrito Federal devem aplicar, em educação, nunca menos de $25 \%$ da receita resultante de impostos, compreendida a receita originária de transferências, na manutenção e desenvolvimento do ensino (MDE). Quanto à organização do ensino, o art. 211 da CF/88 define a atuação dos municípios prioritariamente na Educação Infantil e no Ensino Fundamental, delegando aos estados a atuação prioritária no Ensino Fundamental e Ensino Médio. Com o aumento dos percentuais de impostos vinculados à educação, foi dado novo contorno à educação no País, que conferiu ao Ministério da Educação e Cultura (MEC) condições favoráveis para a formulação e o desenvolvimento de políticas em âmbito educacional.

Segundo Gatti, Barretto e André (2011), após a promulgação da LDB a principal forma de regulação dos recursos destinados aos docentes da educação básica passou a ser feita pelo Fundo de Manutenção e Desenvolvimento do Ensino Fundamental e de valorização do Magistério (FUNDEF), o qual foi instituído pela Emenda Constitucional $n^{\circ} 14$, e regulamentado pela Lei $n^{\circ} 9.424 / 96$, e pelo Decreto $n^{\circ} 2.264$, de julho de 1997. Esse fundo foi implantado em $1^{\circ}$ de janeiro de 1998 e vigorou por dez anos, quando foi substituído pelo atual Fundo de Manutenção e Desenvolvimento da Educação Básica e de Valorização dos Profissionais da Educação (FUNDEB), instituído pela Emenda Constitucional $n^{\circ} 53$, de 19 de dezembro de 2006, e regulamentado pela Lei $n^{\circ} 11.494$, de 28 de julho de 2007.

Conforme as autoras mencionadas, tais fundos criaram dispositivo regular, possibilitando uma maior equidade na manutenção e desenvolvimento do Ensino 
Educação Infantil no Município de Teresina

Fundamental, inicialmente com o Fundef e, posteriormente, de toda Educação Básica com o Fundeb. Ao fomentar o provimento de recursos necessários para a efetivação das políticas de valorização do magistério e favorecer o próprio arcabouço político exigido nos sistemas de ensino para o desenvolvimento profissional dos docentes, esses fundos, devido a sua visão e lógica, foram responsáveis por normatizações básicas para a construção de políticas de valorização do magistério mais equitativas.

Ainda segundo as autoras, o Fundef contribuiu para a efetivação da política de formação docente ao possibilitar que governos de vários estados e municípios estabelecessem novas articulações com instituições formadoras de professores, firmando convênios para o desenvolvimento de programas especiais de licenciatura voltados aos professores em exercício nas redes públicas que possuíam apenas formação em nível médio. Favoreceu-se, dessa forma, a elevação do cumprimento da obrigatoriedade da formação em nível superior para todos os docentes exigida pela LDB, por meio de programas de licenciatura a distância e semipresenciais que utilizavam recursos midiáticos diversos, visto que havia uma demanda tão grande de professores para certificar que os cursos regulares da educação superior, no seu formato clássico, não teriam condições de atender a curto ou médio prazo, uma vez que o $\S 2^{\circ}$ do art. $9^{\circ}$ da Lei do Fundef estabelecia um prazo de cinco anos para que os professores leigos obtivessem a habilitação necessária ao exercício das atividades docentes.

Com a institucionalização do Fundeb, amplia-se o objetivo desses programas, aflorando expectativas positivas, afinal, trata-se de uma legislação que estabelece regras de melhoria para o sistema educacional, pois traz em seu bojo a proveniência dos recursos, o modo de administração destes e, principalmente, o fim visado, qual seja: a manutenção e o desenvolvimento da educação básica pública e a valorização dos trabalhadores em educação, incluindo sua remuneração condigna. Esse novo dispositivo legal representa um avanço no tocante à Educação Infantil, visto contemplar toda a Educação Básica.

\section{O Perfil Formativo dos Docentes da Educação Infantil em Teresina}

Esta investigação evidenciou que, em 2017, existiam em Teresina 294 instituições que ofertavam matrículas para a Educação Infantil, compreendendo creche e pré-escola, sendo $182(61,9 \%)$ pertencentes à Rede Pública Municipal de Ensino de Teresina e $112(38,1 \%)$ da rede privada (compreendendo as escolas particulares, filantrópicas, confessionais e comunitárias). Percebe-se que a referida rede pública detém a maior quantidade de instituições de Educação Infantil em Teresina, isso se deve ao processo de municipalização dessa etapa de ensino, ocasionando a expansão das matrículas na Educação Infantil, por meio de dois movimentos: 1) a passagem do atendimento estadual para o municipal e 2) a passagem das creches, anteriormente vinculadas à Secretaria Municipal da Criança e do Adolescente (SEMCAD ${ }^{4}$ ), para a Secretaria Municipal de Educação (SEMEC). No tocante à quantidade de docentes, do total de 2.342 , mais de dois terços (1.604 professores - 68,5\%) atuavam na Rede Pública Municipal de Ensino de Teresina e $738(31,5 \%)$ trabalharam na rede privada, conforme apresentado na tabela 1.

4 Em 2007, a SEMCAD transforma-se em Secretaria Municipal da Juventude (SEMJUV), pela Lei Complementar $n^{\circ} 3.617$, de 2007. 
Tabela 1 - Docentes na Educação Infantil em Teresina, por dependência administrativa e sexo, em 2017

\begin{tabular}{|c|c|c|c|}
\hline \multirow{2}{*}{ DEPENDÊNCIA ADMINISTRATIVA (ESCOLA) } & \multirow[b]{2}{*}{ TOTAL } & \multicolumn{2}{|c|}{ SEXO } \\
\hline & & Masculino & Feminino \\
\hline \multirow[t]{2}{*}{ Municipal } & 1.604 & 12 & 1.592 \\
\hline & $(68,5 \%)$ & $(0,7 \%)$ & $(99,3 \%)$ \\
\hline \multirow{2}{*}{ Privada } & 738 & 19 & 719 \\
\hline & $(31,5 \%)$ & $2,6 \%$ & $97,4 \%$ \\
\hline \multirow{2}{*}{ Total } & 2.342 & 31 & 2.311 \\
\hline & $100,0 \%$ & $1,3 \%$ & $98,7 \%$ \\
\hline
\end{tabular}

Fonte: MEC/INEP, 2017. Elaborada pelos autores desta pesquisa.

Estabelecendo relação entre a quantidade de docentes por dependência administrativa e sexo, a referida tabela ratifica uma tendência que acontece no magistério na Educação Infantil desde o início da oferta de atendimento a esse público, quando ainda se tratava de atendimento assistencialista, o fato de ser uma profissão desenvolvida, predominantemente, pelo sexo feminino. Acerca disso, os números apontam que quase a totalidade, $99,3 \%$, dos docentes da Rede Pública Municipal de Teresina é constituída por mulheres. Na rede privada, essa realidade não difere muito, $97,4 \%$ dos docentes é do sexo feminino. Segundo Lima (2016), essa feminilização no exercício da docência, nos anos iniciais e, especialmente na Educação Infantil, deve-se ao reconhecimento social da mulher como educadora nata.

Em relação à escolaridade dos professores da Educação Infantil de Teresina, na Tabela 2 (a seguir) chama a atenção o fato de existir ainda $27(1,2 \%)$ professores com apenas o Ensino Fundamental incompleto. Essa constatação torna-se mais grave quando se constata que, há mais de duas décadas, a LDB estabelece formação em curso Normal Magistério de nível médio como exigência mínima para ser professor na Educação Infantil.

No entanto, nas outras etapas da Educação Básica também existe uma quantidade considerável de professores sem a formação em nível superior. Levantamento ${ }^{5}$ de dados, de 2013 a 2016, aponta que houve uma ampliação no percentual de docentes com formação em nível superior, chegando, em 2016, a 46,6\% dos professores atuando na Educação Infantil, $59,0 \%$ atuando nos anos iniciais do Ensino Fundamental, 50,9\% atuando nos anos finais e 60,4\% no Ensino Médio. Entretanto, notas estatísticas do Censo Escolar de 2017 revelam que, dos 2.192.224 docentes que atuavam na Educação Básica no Brasil, 474.679 possuíam apenas o Ensino Fundamental ou Médio.

Assim, apesar de a Meta 15 do PNE determinar que "[...] todos os professores e as professoras da educação básica possuam formação específica de nível superior, obtida em curso de licenciatura na área de conhecimento em que atuam" (BRASIL, 2014), essa meta está longe de ser alcançada, o que confirma o distanciamento que ainda existe entre a legislação e a realidade concreta.

É importante frisar que, em relação aos profissionais que atuam com o público infantil, nem todos exercem a função de titular. Assim, desse quantitativo de docentes, $2.116(90,4 \%)$ atuavam como titulares de sala de aula e 226 (9,6\%) atuavam como auxiliares, em 2017. Para

5 Relatório de monitoramento das metas do PNE (2014-2024), realizado pelo INEP e divulgado em junho de 2018. 
Educação Infantil no Município de Teresina

melhor caracterizar o perfil formativo dos professores que atuaram na Educação Infantil de Teresina naquele ano, consolidaram-se os dados, referentes à escolaridade por dependência administrativa e função que exerce na escola, na Tabela 2.

Tabela 2 - Escolaridade dos docentes da Educação Infantil em Teresina - por dependência administrativa e função que exerce na escola, em 2017

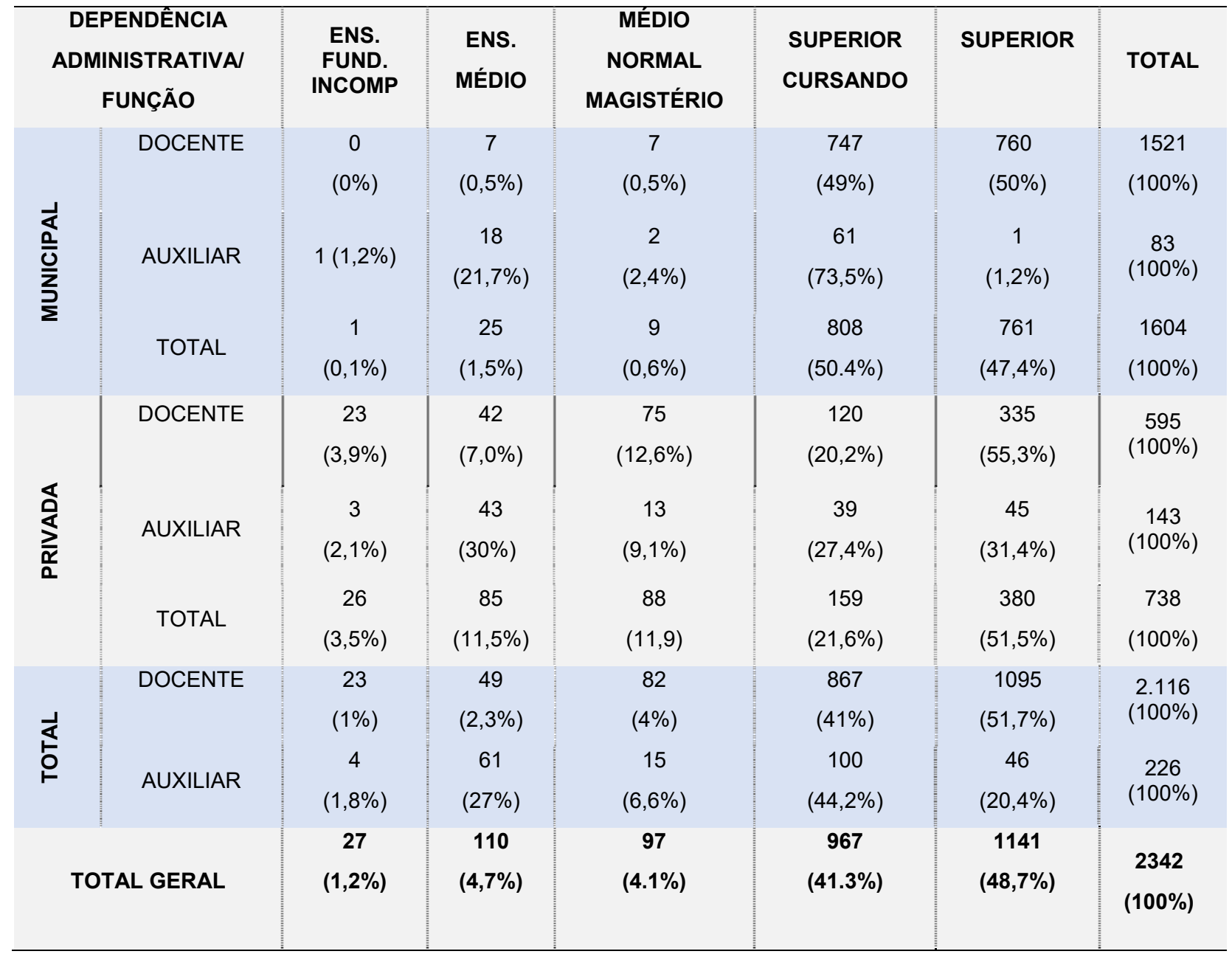

Fonte: MEC/INEP, 2017. Elaborada pelos autores desta pesquisa.

Os dados da Tabela 2 evidenciam que, dos 595 profissionais que atuavam como docente, isto é, como titulares de sala de aula na Educação Infantil na rede privada de ensino de Teresina, $23(3,9 \%)$ possuíam apenas o Ensino Fundamental incompleto e 42 (7,0\%) somente o Ensino Médio completo. Com relação à Rede Pública de Ensino de Teresina, dos 1.521 docentes apenas $7(0,5 \%)$ possuíam somente Ensino Médio.

Com base nos dados desta Tabela 2 foi possível verificar, também, que somente 82 (4\%), dos 2.116 docentes das duas redes de ensino, tinham o curso Normal Magistério de Nível Médio, dos quais 75 são da rede privada. Embora a LDB/96 mantenha esse curso como exigência mínima para atuar na Educação Infantil e anos iniciais do Ensino Fundamental, essa pesquisa revelou um percentual insignificante de docentes com esse perfil, possivelmente devido à extinção dessa formação em Teresina, ao contrário de outros municípios brasileiros, onde ainda é ofertada, embora o curso Normal Magistério de Nível Médio tenha perdido 
Educação Infantil no Município de Teresina

espaço e prestígio para a formação de nível superior desde a aprovação da referida lei. Segundo Lima (2016, p. 259),

\begin{abstract}
Esses cursos continuam em funcionamento em muitos estados brasileiros de acordo com a Sinopse Estatística da Educação Básica de 2014, disponível do site do INEP, e em vários deles, com um número significativo de matrículas. O Piauí, de acordo com esses dados, não é um desses casos, haja vista não haver nenhum registro desse tipo de curso.
\end{abstract}

A não oferta do Normal Magistério de Nível Médio, no Piauí e em outros estados do Brasil, é motivada pela expansão da política de formação de professores em nível superior, implantada pelo MEC e efetivada por meio de diversos programas, principalmente o Universidade Aberta do Brasil (UAB) e o Plano Nacional de Formação de Professores da Educação Básica (PARFOR).

No tocante à materialização desses cursos da UAB no Piauí, segundo Lima (2016), se efetivou através da Universidade Estadual do Piauí (UESPI), que contava, entre 2014 e 2015, com 24 polos e, na metade deles, o curso de Licenciatura em Pedagogia é oferecido, contribuindo assim para absorver parte dessa demanda por formação. A outra IES, que é integrante da UAB no Piauí, é a Universidade Federal do Piauí (UFPI), que conta, no período em referência, com 21 polos, dos quais apenas em três deles o curso de Licenciatura em Pedagogia é ofertado.

Com relação à formação, em nível superior, dos profissionais que atuaram como docentes nas creches e pré-escolas, em 2017, constatou-se que um expressivo número de docentes da Rede Pública Municipal de Ensino de Teresina, 747 dos 1.521, o que corresponde a $49 \%$, ainda estava cursando o ensino superior. $\mathrm{Na}$ rede privada esse percentual equivaleu a 20,2\%, 120 dos 595 docentes.

A constatação de que muitos docentes estavam cursando ensino superior pode revelar, por um lado, avanços em relação ao alcance da meta 15 do PNE, por outro lado, hipoteticamente, pode indicar a presença de muitos estagiários atuando como titular de sala de aula na Educação Infantil, o que precisa ser melhor investigado. Nesse sentido, espera-se que outros estudos, utilizando abordagem no campo das pesquisas qualitativas, possam explicar quem são os docentes que atuam na Educação Infantil sem curso superior completo.

Os dados apresentados revelam, também, que dos 2.342 profissionais (docentes e auxiliares) da Educação Infantil de Teresina da rede pública municipal e privada, em 2017, $1.141(48,7 \%)$ possuíam curso superior. Um percentual menor que o do Brasil, que é de $66,4 \%$, de acordo com notas estatísticas do censo escolar do referido ano. Considerando somente os profissionais que atuavam nas mencionadas redes de ensino como docente, ou seja, como titular de sala de aula, esse percentual sobe de $48,7 \%$ para $51,7 \%$.

Entretanto, não basta apenas ter curso superior, esta formação, de acordo com o artigo 62 da LDB, deve ser em curso de licenciatura. Assim, a Tabela 3 apresenta o quantitativo de docentes com licenciatura na primeira graduação e na segunda graduação por dependência Administrativa. 
Educação Infantil no Município de Teresina

Tabela 3 - Docentes com licenciatura na primeira e na segunda graduação, na Educação Infantil de Teresina, por dependência Administrativa, em 2017

\begin{tabular}{c|c|c|c|c}
\hline $\begin{array}{c}\text { DEPENDÊNCIA } \\
\text { ADMINISTRATIVA } \\
\text { (ESCOLA) }\end{array}$ & $\begin{array}{c}\text { LICENCIATURA } \\
\text { GRADUAÇÃO 1 }\end{array}$ & $\begin{array}{c}\text { LICENCIATURA } \\
\text { GRADUAÇÃO 2 }\end{array}$ & $\begin{array}{c}\text { TOTAL } \\
\text { LICENCIATURAS }\end{array}$ & $\begin{array}{c}\text { TOTAL } \\
\text { DE GRADUAÇÕES }\end{array}$ \\
\hline Municipal & 1.556 & 13 & 1.569 & 1.569 \\
Privada & 485 & 1 & 486 & 539 \\
Total & 2.041 & 14 & 2055 & 2.108 \\
\hline
\end{tabular}

Fonte: MEC/INEP, 2017. Elaborada pelos autores desta pesquisa.

A Tabela 3 mostra que, dos 539 profissionais da Educação Infantil da rede privada de ensino, considerando todos os docentes e auxiliares que possuíam curso superior ou que estavam cursando, somente $486(91,2 \%)$ possuía ou faziam algum curso de licenciatura. Já na Rede Pública Municipal de Ensino de Teresina, dos 1.569 profissionais da Educação Infantil que possuíam curso superior ou que estavam cursando, 100\% eram de licenciatura, sendo 1.556 na graduação e 13 na segunda.

$\mathrm{Na}$ Tabela 4, detalham-se melhor os dados sobre a formação na primeira graduação, dos docentes da educação infantil em Teresina, apresentando o tipo do curso por dependência administrativa, envolvendo tanto os profissionais que já possuíam o ensino superior, quanto os que ainda o estavam cursando em 2017.

Tabela 4 - Tipo da primeira graduação por dependência administrativa

\begin{tabular}{c|c|c|c|c}
\hline $\begin{array}{c}\text { DEPENDÊNCIA ADMINISTRATIVA } \\
\text { (ESCOLA) }\end{array}$ & \multicolumn{2}{|c|}{ LICENCIATURA } & \multirow{2}{*}{ BACHARELADO } & TOTAL \\
& PEDAGOGIA & OUTRAS & 13 & 1.569 \\
& 1.534 & 22 & $(0,8 \%)$ & $(100 \%)$ \\
MUNICIPAL & $(97,8 \%)$ & $(1,4 \%)$ & & 539 \\
& 384 & 101 & $(10,0 \%)$ & $(100 \%)$ \\
PRIVADA & $(71,3 \%)$ & $(18,7 \%)$ & & 2108 \\
& 1.918 & 123 & 67 & $(100 \%)$ \\
\hline TOTAL & $(91 \%)$ & $(5,8 \%)$ & $(3,2 \%)$ & \\
\hline
\end{tabular}

Fonte: MEC/INEP, 2017. Elaborada pelos autores desta pesquisa.

Conforme a Tabela 4, considerando a primeira graduação dos docentes da Educação Infantil, 97,8\% dos cursos dos profissionais que atuavam na Educação Infantil na Rede Pública Municipal de Ensino de Teresina era de Licenciatura em Pedagogia. Resultado que revela existir um significativo avanço em relação ao alcance da meta 15 do PNE, a qual estabelece que a formação do docente para atuar na Educação Básica deve ser em licenciatura na área do conhecimento em que atua.

Acredita-se que esse elevado índice de professores com licenciatura em Pedagogia deve-se a dois fatores: 1) a forma de ingresso por meio de concurso público de provas e 
Educação Infantil no Município de Teresina

títulos, tendo como requisito a formação na área específica garantida pela CF de 88 ; 2) a política nacional de formação dos profissionais da educação em regime de colaboração entre a União, os estados, o Distrito Federal e os municípios efetivada pelo MEC por meio do PARFOR, que oferta três tipos de formação: 1) cursos de $1^{a}$ licenciatura, voltados para docentes que não possuem formação superior; 2) cursos de $2^{\mathrm{a}}$ licenciatura para os docentes que possuem licenciatura em área distinta de sua atuação em sala de aula; 3) formação pedagógica para os docentes que possuem curso superior, sem habilitação em licenciatura.

Ademais, a expansão do Sistema Universidade Aberta do Brasil (UAB) ampliou a oferta e a quantidade de concludentes em cursos de graduação, especialmente nos cursos de licenciatura.

É importante salientar que, embora o art. $62, \S 3^{\circ}$ da LDB estabeleça que "[...] a formação inicial de profissionais de magistério dará preferência ao ensino presencial, subsidiariamente fazendo uso de recursos e tecnologias de educação à distância", com a expansão das matrículas nos cursos superiores na primeira década deste século, sobretudo da licenciatura em Pedagogia, houve uma transformação nas características da oferta desses cursos. Acerca disso, Barretto (2015, p. 682) afirma,

\begin{abstract}
De acordo com os censos da educação superior, em 2001 havia 53,8\% das matrículas no setor privado e $46,2 \%$ na rede pública, e estas eram oferecidas praticamente só na modalidade presencial, fundamentalmente pelas instituições de ensino superior (IES) estaduais e federais. Em 2011, a proporção entre as matrículas presenciais do setor privado e do setor público não sofre alterações substantivas (56,7\% e 43,3\%). No entanto, as matrículas a distância fazem toda a diferença: elas saltaram de insignificante $0,6 \%$ para $31,6 \%$ em 2011. Nesse interregno, as matrículas nos cursos de pedagogia passaram de $29,3 \%$ a $65,7 \%$ do total de estudantes.
\end{abstract}

Vale ressaltar também que, ainda segundo o autor referenciado, com a ampliação da oferta dos cursos de licenciatura na modalidade a distância, o Estado transfere à iniciativa privada a maior parte de suas responsabilidades em relação à formação de professores.

$\mathrm{Na}$ rede privada, considerando a primeira graduação, os cursos dos profissionais que atuavam na Educação Infantil possuem uma configuração um pouco diferente, pois apenas $71,3 \%$ dos docentes, em 2017, tinham ou cursavam Licenciatura em Pedagogia, observandose a presença de um percentual considerável de profissionais com bacharelado $(10,0 \%)$ e outras licenciaturas (18,7\%), ou seja, $28,7 \%$ dos professores da Educação Infantil da rede privada de Teresina não possuíam, em 2017, formação específica ou compatível para atuar nessa importante etapa da Educação Básica. Esse menor percentual de docentes com licenciatura em Pedagogia deve-se, presume-se, ao fato de não haver um maior rigor no momento da contratação do professor, sobretudo em escolas particulares de pequeno porte, assim como o fato de estes profissionais não serem contemplados com programas como o PARFOR, que é destinado apenas para os profissionais do magistério que estejam no exercício da docência na rede pública de Educação Básica.

\title{
Considerações Finais
}

Os dados da pesquisa revelaram que, apesar dos avanços, o perfil de formação dos professores é diversificado, pois, além da presença dos professores com curso de licenciatura e curso Normal Magistério de nível médio atuando nas creches e pré-escolas de Teresina, o 
Educação Infantil no Município de Teresina

que atende às exigências mínimas da LDB, existem ainda alguns professores com Ensino Fundamental incompleto e um significativo número de docentes com nível médio (sem magistério), estando em desacordo com a exigência dessa Lei.

Quando se comparou os tipos de cursos da primeira graduação dos professores da educação infantil das redes pública municipal e privada, constatou-se que a grande maioria dos titulares de turmas da rede pública municipal tinha ou cursava Licenciatura em Pedagogia $(97,8 \%)$, enquanto que os profissionais que atuavam na rede privada possuíam uma configuração um pouco diferente, pois apenas $71,3 \%$ dos docentes, em 2017 , tinham ou cursavam Licenciatura em Pedagogia, observando-se a presença de um percentual considerável de profissionais com bacharelado $(10,0 \%)$ e outras licenciaturas $(18,7 \%)$, ou seja, $28,7 \%$ dos professores da Educação Infantil da rede privada de Teresina não possuíam em 2017 formação específica ou compatível para atuar nessa etapa da Educação Básica.

As conclusões deste estudo mostraram que o perfil formativo diversificado dos professores da Educação Infantil em Teresina, quantitativamente, nega que a docência, nessa etapa da Educação Básica, é um ofício com especificidades que precisam ser aprendidas e que a caracterizam e a difere das demais profissões, e até mesmo da própria docência em outras etapas e níveis de ensino, o que pode prejudicar o alcance das finalidades estabelecidas pela LDB.

Contudo, tendo em vista o elevado percentual de docentes que atuavam na Educação Infantil de Teresina que já possuíam ou estavam cursando licenciatura em Pedagogia, em 2017, sobretudo na Rede Pública Municipal de Ensino de Teresina, considera-se um significativo avanço em relação ao cumprimento do que estabelece a LDB em relação à formação dos docentes da Educação Básica e, consequentemente, ao alcance da meta 15 do PNE, podendo-se projetar uma melhoria desse perfil formativo a curto ou médio prazo.

\section{Referências}

BARRETTO, Elba. Siqueira de Sá. Políticas de Formação Docente para a Educação Básica no Brasil: embates contemporâneos. Revista Brasileira de Educação, Rio de Janeiro, v. 20, n. 62, jul./set. 2015. Disponível em: <http://dx.doi.org/10.1590/S1413-24782015206207>. Acesso em: 17 set. 2018.

BRASIL. Lei no 9.394, de 20 de dezembro de 1996, dispõe sobre as Diretrizes e Bases da Educação Nacional. Diário Oficial da União, Brasília, 1996. Disponível em: <http://portal.mec.gov.br>. Acesso em: 16 jun.2018.

BRASIL. Lei $n^{\circ}$ 11.494, de 20 de junho de 2007. Regulamenta o Fundo de Manutenção e Desenvolvimento da Educação Básica e de Valorização dos Profissionais da Educação FUNDEB, de que trata o art. 60 do Ato das Disposições Constitucionais Transitórias; altera a Lei no 10.195, de 14 de fevereiro de 2001; revoga dispositivos das Leis nos 9.424, de 24 de dezembro de 1996, 10.880, de 9 de junho de 2004, e 10.845, de 5 de março de 2004; e dá outras providências. Diário Oficial da União, Brasília, 2007. Disponível em: <http://www.planalto.gov.br/ccivil_03/_ato2007-2010/2007/lei//11494.htm>. Acesso em: 16 jun. 2018. 
Educação Infantil no Município de Teresina

BRASIL. Lei n 13.005, de 25 de junho de 2014. Aprova o Plano Nacional de Educação - PNE e dá outras providências. Diário Oficial da União, Brasília, 2014. Disponível em: <http://www.planalto.gov.br>. Acesso em: 02 jun. 2017.

BRASIL. Ministério da Educação. Secretaria de Educação Básica. Parâmetros Nacionais de Qualidade para a Educação Infantil. Brasília, 2006. Disponível em: $<$ http://portal.mec.gov.br/seb/arquivos/pdf/Educinf/eduinfparqualvol1.pdf>. Acesso em: 03 set. 2018.

BRASIL. Ministério da Educação. Secretaria de Educação Básica. Diretrizes curriculares nacionais para a educação infantil. Brasília: MEC, SEB, 2010.

BRASIL. Instituto Nacional de Estudos e Pesquisas Educacionais Anísio Teixeira (INEP). Nota técnica $n^{\circ}$ 020/2014. Brasília, 21 de novembro de 2014. Disponível em: <http://inep.gov.br/web/guest/sinopses-estatisticas>. Acesso em: 16 jun.2018.

BRASIL. Instituto Nacional de Estudos e Pesquisas Educacionais Anísio Teixeira (INEP). Relatório de Monitoramento das Metas do PNE (2014-2024). Brasília, 2014. Disponível em: <http://inep.gov.br>. Acesso em: 03 set. 2018.

GATTI, Bernadete Angelina. Pesquisar em educação: considerações sobre alguns pontoschave. Diálogo Educacional, Curitiba, v. 6, n. 19, p. 25-35, set./dez. 2006. Disponível em: <http://www2.pucpr.br/reol/index.php/DIALOGO?dd1=235>. Acesso em: 26 jun. 2018.

GATTI, Bernadete Angelina; BARRETTO, Elba Siqueira de Sá (Coord.). Professores do Brasil: impasses e desafios. Brasília, DF: UNESCO, 2009.

GATTI, Bernadete Angelina; BARRETTO, Elba Siqueira de Sá; ANDRÉ, Marli Eliza Dalmazo de Afonso. Políticas docentes no Brasil: um estado da arte. Brasília: UNESCO, 2011.

LIMA, Maria Carmem Bezerra. Quem são os professores da primeira infância?: Um estudo sobre o perfil formativo dos professores que atuam na Educação Infantil no estado do Piauí no contexto pós LDB 9.394/96. 2016. Tese (Doutorado em Educação) - Universidade Federal do Piauí, Teresina, 2016.

LIMA, Maria José Rocha; DIDONET, Vital (Org.). FUNDEB - Fundo de Manutenção e Desenvolvimento da Educação Básica e de Valorização dos Profissionais da Educação: Avanços na universalização da educação básica. Brasília: Inep, fev. 2006. Disponível em: <http://portal.inep.gov.br/documents/186968/484184/Fundeb+avanços+na+universalização+ da+educação+básica/9be4477d-88b3-4fe8-a3bc-fc263d878002?version=1.1>. Acesso em: 16 set. 2018.

Sandra Regina de Morais Cunha Rodrigues é mestranda pelo Programa de Pós-Graduação em Educação da Universidade Federal do Piauí-PPGEd/UFPI. Professora do Instituto Federal do Piauí-IFPI de Disciplinas Pedagógicas e Língua Brasileira de sinais-LIBRAS. Membro do Núcleo de Estudos e Pesquisas em Políticas e Gestão da Educação-NUPPEGE.

E-mail: sandra.morais@ifpi.edu.br 
Educação Infantil no Município de Teresina

Luis Carlos Sales é Professor Doutor do Programa de Pós-Graduação em Educação da Universidade Federal do Piauí- PPGED/UFPI.

E-mail: Iwis2006@gmail.com

Recebido em 15 de outubro de 2018

Aprovado em 12 de novembro de 2018 


\title{
Editores do volume 8
}

José Marcelino de Rezende Pinto - Universidade de São Paulo, São Paulo/SP, Brasil

Nalú Farenzena - Universidade Federal do Rio Grande do Sul, Porto Alegre/RS, Brasil

\section{Comitê Editorial}

José Marcelino de Rezende Pinto - Universidade de São Paulo, Brasil

Juca Gil - Universidade Federal do Rio Grande do Sul, Brasil

Theresa Adrião - Universidade Estadual de Campinas, Brasil Ângelo

Ricardo de Souza - Universidade Federal do Paraná, Brasil

Márcia Aparecida Jacomini - Universidade Federal de São Paulo, Brasil

\section{Conselho Editorial}

\section{Alejandro Morduchowicz}

Universidad Pedagógica, Provincia de Buenos Aires, Argentina

Fernanda Saforcada

Universidade de Buenos Aires, Argentina

Jacques Velloso

Universidade de Brasília, Brasil

João Monlevade

Senado Federal, Brasil

Jorge Abrahão de Castro

Instituto de Pesquisa Econômica Aplicada / IPEA, Brasil

Juca Gil

Universidade Federal do Rio Grande do Sul, Brasil

Lisete Regina Gomes Arelaro

Universidade de São Paulo, Brasil

Luis Carlos Sales

Universidade Federal do Piauí, Brasil

Luiz de Sousa Junior

Universidade Federal da Paraíba, Brasil

Luiz Fernandes Dourado

Universidade Federal de Goiás, Brasil

Magna França

Universidade Federal do Rio Grande do Norte, Brasil

\section{Maria Beatriz Luce}

Universidade Federal do Pampa, Brasil

Universidade Federal do Rio Grande do Sul, Brasil

Marcos Edgar Bassi

Universidade Federal do Paraná, Brasil

\author{
Maria Dilnéia Espíndola Fernandes \\ Universidade Federal de Mato Grosso do Sul, Brasil \\ Nalú Farenzena \\ Universidade Federal do Rio Grande do Sul, Brasil \\ Nelson Cardoso do Amaral \\ Universidade Federal de Goiás, Brasil \\ Nicholas Davies \\ Universidade Federal Fluminense, Brasil \\ Rosana Evangelista Cruz \\ Universidade Federal do Piauí, Brasil \\ Rosana Gemaque \\ Universidade Federal do Pará, Brasil \\ Robert E. Verhine \\ Universidade Federal da Bahia, Brasil \\ Romualdo Portela de Oliveira \\ Universidade de São Paulo, Brasil \\ Theresa Adrião \\ Universidade Estadual de Campinas, Brasil \\ Tristan McCowan \\ University of London, Reino Unido \\ Vera Jacob \\ Universidade Federal do Pará, Brasil \\ Vera Peroni \\ Universidade Federal do Rio Grande do Sul, Brasil \\ Vitor Henrique Paro \\ Universidade de São Paulo, Brasil
}

\section{Equipe editorial}

Apoio ao Comitê Editorial: Patrícia Balthazar Garcia

Diagramação, Revisão de português e normalização: Edson Leonel de Oliveira

Revisão de inglês: Ananyr Porto Fajardo 